\title{
Generation and clonal isolation of retinal stem cells from human embryonic stem cells
}

\author{
Laura Clarke ${ }^{a,}{ }^{,}$, Brian G. Ballios ${ }^{a}$, and Derek van der Kooy ${ }^{a, b}$ \\ anstitute of Medical Science, University of Toronto, 1 King's College Circle, Toronto, Ontario M5S \\ 1A8, Canada \\ bDepartment of Molecular Genetics, University of Toronto, 1 King's College Circle, Toronto, \\ Ontario M5S 1A8, Canada
}

\begin{abstract}
Retinal stem cells (RSCs) are present within the pigmented ciliary epithelium (CE) of the adult human eye and produce progeny that differentiate in vitro into all neural retinal subtypes and retinal pigmented epithelium (RPE). We hypothesized that a RSC population, similar to the adult CE-derived RSC, is contained within pigmented colonies that arise in long-term cultures of hESCs suggested to recapitulate retinal development in vitro. Single pigmented hESC-derived cells were isolated and plated in serum-free media containing growth factors and, after 2 weeks, clonal sphere colonies containing both pigmented and nonpigmented cells were observed. These colonies expressed the early retinal transcription factors Rx, Chx10 and Pax6, and could be dissociated and replated as single cells to form secondary clonal colonies. When allowed to differentiate, expression of markers for both RPE and neurons was observed. Rhodopsin expression was detected after explant coculture and transplantation into the developing mouse eye as well as following treatment with soluble factors in vitro. We show that RSCs emerge in an in vitro model of retinal development and are a potential source of human photoreceptors for use in transplantation.
\end{abstract}

\section{Keywords}

human embryonic stem cell; differentiation; self-renewal; retinal stem cell; photoreceptor

\section{Introduction}

Rare, pigmented cells present in the $\mathrm{CE}$ of the adult human and mouse eye compose a population of retinal stem cells (RSCs) (Tropepe et al., 2000; Ahmad et al., 2000; Coles et al., 2004). Though quiescent in vivo, isolated single stem cells proliferate to form sphere colonies which consist of both heavily pigmented and lightly or nonpigmented cells. These clonal spheres have the capacity for long-term self-renewal and multilineage retinal differentiation in vitro and can contribute to the RPE and neural retina after transplantation (Inoue et al., 2010; Ballios and van der Kooy, 2010).

The mammalian eye develops from an evagination of anterior neural tissue termed the optic vesicle. Progenitors competent to form both RPE and NR express a set of eye field transcription factors including Pax6, Otx2, Rx and Six3 (Oliver et al., 1995; Grindley et al.,

*Corresponding author: The Donnelly Centre, 160 College St. 11 ${ }^{\text {th }}$ Floor, Toronto, Ontario, Canada, M5S 3E1, Phone: 416-978-4539, Fax: 416-978-2666, laura.clarke@utoronto.ca.

The authors indicate no potential conflicts of interest. 
1995; Furukawa et al., 1997; Zuber et al., 2003). The optic vesicle is then rapidly segregated into the inner presumptive neural retina and the outer presumptive RPE, which later becomes pigmented (Kaufman, 1992; Graw, 2010). The outer, pigmented layer of the CE where RSCs are found is continuous with the RPE. RSCs express genes essential for retinal development such as the neural retina transcription factor Chx10 and Pax6, which is necessary for RSC proliferation (Tropepe et al., 2000; Xu et al., 2007).

Pigmented cells have been reported to arise from primate and human ESCs (hESCs) that were allowed to differentiate for several weeks on stromal or fibroblast feeder layers (Kawasaki et al., 2002; Klimanskaya et al., 2004). These cells can be isolated and expanded to give rise to monolayers of RPE cells that express appropriate markers, have capacity to phagocytose and can rescue photoreceptor loss in RCS rats (Lund et al., 2006) We asked whether pigmented cells spontaneously arising in differentiated hESCs contained a subpopulation of RSCs: single pigmented cells with the capacity for both self-renewal and multilineage retinal differentiation. Such a population would potentially be useful as a retinal specific donor cell population for cell-based therapies to treat degenerative diseases of the eye, particularly as protocols to differentiate hESCs to pigmented cells appear to be easily translated to induced pluripotent stem cells (iPSCs) (Hirami et al., 2009; Meyer et al., 2009).

\section{Materials and Methods}

\section{hESC culture}

H9 cells were maintained in knock-out DMEM with $20 \%$ knockout serum replacement, $1 \%$ Glutamax $^{\mathrm{TM}}, 1 \%$ beta-mercaptoethanol, $1 \%$ non-essential amino acids and $4 \mathrm{ng} / \mathrm{ml}$ of FGF2 on inactivated mouse embryonic fibroblasts (MEFs). Cells were passaged using collagenase type IV onto fresh, irradiated MEFs at a ratio of 1:6 every 5 days or at $80 \%$ confluency (whichever came first). Pluripotency marker testing (SSEA3 and Tra-1-60) through FACS was performed every 4 th passage; cells were discarded below 70/65 respectively.

\section{hESC differentiation}

H9 hESCs were differentiated into pigmented cells as described (Kawasaki et al., 2002; Klimanskaya et al., 2004). Briefly, H9 hESCs were either overgrown on mouse embryonic fibroblasts (MEFs) and then switched to a media containing $13 \% \mathrm{KnockOut}^{\mathrm{TM}}$ serum replacement in Knock Out ${ }^{\mathrm{TM}}$-DMEM (Gibco), or were grown on PA6 stromal cells in GMEM (Sigma-Aldrich) containing $10 \%$ KnockOut $^{\mathrm{TM}}$ serum replacement. Media was changed every 1-2 days. Pigmented colonies arose after 3-5 weeks. CA1 hESCs also gave rise to pigmented colonies under the same conditions.

\section{Sphere-forming assay}

Pigmented patches were picked using a pipette and dissociated into single cells using trypsin-EDTA. Cell viability was assessed immediately before plating using Trypan blue exclusion and cells were plated at 5 cells $/ \mu \mathrm{L}\left(1389 / \mathrm{cm}^{2}\right)$ in serum-free media containing $10 \mathrm{ng} / \mathrm{mL}$ FGF2, $2 \mu \mathrm{g} / \mathrm{mL}$ heparin (both from Sigma) and B27 (Gibco) in 24-well plates $\left(\right.$ Nunclon $\left.^{\mathrm{TM}}\right)$. The media was carefully refreshed once after approximately 10 days. Colonies were counted after 14-21 days. When indicated, the Rho kinase (ROCK) inhibitor Y-27632 (Calbiochem) was added to the media at a final concentration 10 $\mu \mathrm{M}$ (Watanabe et al., 2007).

\section{Flow cytometry}

Differentiated hESC monolayers were dissociated into single cells using trypsin-EDTA and plated at $1-2$ million cells $/ 75 \mathrm{~cm}^{2}$ flask (Nunclon ${ }^{\mathrm{TM}}$ ) in serum-free media with FGF, heparin 
and B27 and allowed to proliferate for 5-7 days. Small sphere colonies were then dissociated a second time using $20 \mathrm{U} / \mathrm{mL}$ papain in trypsin-EDTA and analyzed on a FACS Aria (BD Biosciences). A combination of side and forward scatter was used to delineate the fraction containing pigmented cells. Dissociated, non-pigmented neural colonies obtained from hESCs were used as a negative control.

\section{Ficoll gradient}

A 25\% stock solution of ficoll (Sigma) was prepared in Hank's balanced salt solution (HBSS) and autoclaved, then diluted in HBSS. $16 \mathrm{~mL}$ of $15 \%, 8 \mathrm{~mL}$ of $10 \%$ and $8 \mathrm{ml}$ of $5 \%$ ficoll were layered in a $50 \mathrm{~mL}$ Falcon tube and cells were separated by centrifugation for 20 minutes at 2000rpm (Heller and Jones, 1980).

\section{Sphere passaging}

Single spheres were selected and dissociated using trypsin-EDTA and 20units/mL papain (Worthington) for 5 minutes at $37^{\circ}$ followed by brief manual trituration. Dissociation to single cells was verified after plating in individual wells of 48 -well plates in serum-free media with B27, FGF and heparin. ROCK inhibitor was added where noted.

\section{Sphere differentiation}

Spheres were selected onto individual wells of laminin-coated 24-well plates and allowed to attach (laminin from Sigma). Differentiation media either consisted of serum-free media with B27 and 1\% FBS with FGF2 and heparin alone or with the addition of $100 \mu \mathrm{M}$ taurine and 500nM RA (both from Sigma).

\section{Explant cultures}

Retinal explants from adult male and female C57B1/6 mice were cultured as described (Lamba et al., 2006). The intact retina excluding the RPE was removed in aCSF. Small incisions in the periphery were made to flatten the retinas, which were then placed photoreceptor side down on CM $0.4 \mu \mathrm{m}$ cell culture inserts (Millipore) in DMEM/F12 containing 10\% FBS and N2 supplement just covering the tissue. Media was changed every second day.

\section{Immunocytochemistry}

Immunostaining was performed as previously described (Coles et al., 2004). Cells were fixed with $4 \%$ paraformaldehyde for 20 minutes at room temperature, washed in phosphatebuffered saline and permeabilized in 0.3\% Triton X-100 (Sigma) before being blocked for 1 hour in $10 \%$ normal goat serum and incubated overnight in primary antibody at $4^{\circ} \mathrm{C}$. The following primary antibodies were used: mouse anti rhodopsin (RetP1 1:250 and Rho1D4 1:500, Millipore), mouse anti-Pax6 (1:300, Developmental Studies Hybridoma Bank), rabbit anti-Chx10 (a gift from Dr R. McInnes), mouse anti-bestrophin (1:500), mouse anticalbindin (1:500), anti-Cralbp (1:500, Abcam) and anti-GFP (1:500, Invitrogen). All antibodies were tested on sections of mouse neural retina/RPE to confirm cell type specific staining (see also Coles et al., 2004; Ballios et al., 2012). Cells were then rinsed in PBS and incubated in Alexa-tagged secondary antibodies (Molecular Probes, Invitrogen) at 1:400 for 1 hour at $37^{\circ} \mathrm{C}$, rinsed and counterstained with Hoechst 33342 (Invitrogen). Cells were visualized in PBS at room temperature using a Zeiss Axiovert inverted fluorescence microscope and images were acquired with AxioVision v4.6 imaging software and AxioCam MRm camera with monochrome CCD sensor. 


\section{Quantitative RT-PCR}

RNA was extracted using a Qiagen RNeasy extraction kit with DNase to remove genomic DNA contamination. RNA was quantified using Nanodrop and a specified amount of cDNA was reverse-transcribed using SuperscriptIII (Invitrogen). PCR was carried out using standardized Taqman Gene Expression Assays for in a 7900HT Fast Real-Time PCR System (Applied Biosystems). Quantification was performed using the delta $\mathrm{Ct}$ method with $18 \mathrm{~S}$ or Gapdh as an endogenous control template.

\section{Transplantation}

Experimental procedures were performed in accordance with the Guide to the Care and Use of Experimental Animals and approved by the Animal Care Committee at the University of Toronto. Pigmented cells were isolated by FACS and infected with eGFP lentivirus (a gift from Dr. John Dick) 6-12 hours after plating. Spheres were then grown for 3-4 weeks before being dissociated into a single cell suspension using $20 \mathrm{U} / \mathrm{mL}$ papain in trypsinEDTA. NOD/SCID pups aged 0-2 days were anaesthetized using isoflurane and 5-10,000 cells were transplanted into the vitreous fluid using a glass pipette. Confocal images of transplanted eyes were acquired with an Olympus Fluoview 1000 and FV10-ASW 2.0 imaging software.

\section{Statistics}

Student's t-tests were used for comparison of 2 groups and ANOVA with multiple comparisons and posthoc Bonferroni tests were used for multiple comparison and were performed using Prizm statistical software with an overall significance level of 0.05.

\section{Results}

\section{Rare pigmented cells from differentiated hESCs are proliferative retinal progenitors}

Pigmented colonies arose within differentiating hESCs (H9 and CA1) after approximately 4 weeks in culture on PA6 stromal cells or 5 weeks in culture on fibroblast feeders. These colonies were found adjacent to Tuj1-postive cells as well as Pax6-positive neural or retinal precursors and Chx10 positive neural retinal precursors (Figure 1A). mRNAs for Rx, Pax6 and Mitf, genes expressed during eye field specification, were upregulated before the appearance of pigmentation, indicating that unspecified retinal progenitor cells are present before the appearance of RPE and RPE precursor cells (Figure 1B). By immunocytochemistry, we found many non-pigmented, Chx10 and Pax6-positive cells representing proliferating precursors. Pigmented colonies derived in these culture conditions have been presumed to contain only RPE-lineage cells (Kawasaki et al., 2002; Klimanskaya et al., 2004). Pax6 is expressed in RPE progenitors (Quinn et al., 1996; Bäumer et al., 2003), and expression was seen in pigmented cells, though pigmentation often masked immunofluorescence particularly in multilayered colonies (Figure 1C). In areas where pigmented cells were well spread, we noticed a small subset of pigmented cells that were double positive for Pax6 and Chx10. This rare subset may represent a RSC population.

Chx10 is only expressed in the early neural retina and in RSCs (Liu et al., 1994). This suggested the presence of pigmented RSCs in hESC cultures. To investigate this possibility, we employed a clonal, sphere formation assay. Pigmented cell patches were removed using a pipette and dissociated into a single cell suspension and then plated at 5 cells $/ \mu \mathrm{L}$ in serumfree media containing FGF. We found that in 2-3 weeks, similar to the time required to form clonal brain neural colonies from hESCs (Chaddah et al., 2012), colonies composed of both pigmented and non-pigmented cells were present. These were similar in appearance to colonies derived from human CE (Coles et al., 2004), and formed at a low frequency (approximately 1 in 500 pigmented cells from MEF cultures, 1 in 1000 from PA6 cultures, 
$\mathrm{n}=2$ ). The relative rarity of colony-forming cells suggested that only a subset of pigmented cells are proliferative RSCs and that other cells are likely committed RPE cells.

\section{Single pigmented colony-forming precursor cells can be isolated using FACS}

Hand-picking colonies gave a high purity of pigmented cells, however, it did not allow for efficient isolation of large numbers of pigmented cells. We determined whether pigmented cells could be isolated using FACS based on side scatter. Entire differentiated hESC monolayers containing pigmented patches were first dissociated into single cells and allowed to proliferate in serum-free media for 5-7 days, then dissociated a second time and analyzed. For comparison, hESCs in maintenance conditions were cultured under the same conditions. We found that in cells from the differentiated cultures containing pigmented colonies, a population of cells with high side scatter was visible (Figure 2A). By visual inspection, the starting population contained approximately $8.7 \pm 2.7 \%(\mathrm{n}=9)$ pigmented cells, and the high side scatter fraction contained $>95 \%$ pigmented cells. This high purity pigmented population gave rise to clonal colonies mottled with pigmentation, suggesting proliferation of the starting pigmented cell to give rise to separate pigmented or non pigmented cells (Figure 2B, C). A second method of purifying pigmented cells was also tested. A 15\%/10\%/5\% ficoll density gradient was used and similarly resulted in a pigmented population containing rare, colony-forming cells (Figure 2C). The recovery rates using ficoll $(4.9 \pm 2.4 \%)$ and that using FACS $(5.6 \pm 1.6 \%)$ were not significantly different $\left(\mathrm{F}_{1,11}=0.59, \mathrm{p}>0.5\right)$, nor was there an effect of adding the survival factor ROCK inhibitor $\left(\mathrm{F}_{1,11}=0.54, \mathrm{p}>0.5\right)$, known to promote survival of hESCs after dissociation (Watanabe et al., 2007). In ficoll purified cultures, however, we observed rare, non-pigmented colonies, likely neural stem cell-derived neurospheres. Colony-forming neural stem cells are present in differentiating hESC colonies (Chaddah et al., 2012) and would be expected in our culture conditions as cells first adopted a neural identity and then a subset became specified to retinal fate. We used FACS to obtain all subsequent colonies.

Using a FACS purification strategy also allowed us to sort single cells into individual wells of 96-well plates. The presence of only a single pigmented cell (97.8\% of well) or single nonpigmented cell (2.2\% of wells) was visually confirmed for each individual well. The frequency of colony formation from single pigmented cells was very similar to bulk cultures, indicating that spheres are clonally derived. 3 colonies were derived from 1,614 single cells from MEF cultures ( $0.19 \%$ colony formation), compared to 4.1 per 2,500 cells in control bulk culture $(0.16 \%$ colony formation) (Figure 2D). We also observed 8 colonies per 2,823 cells from PA6 cultures in a separate experiment. (0.28\% colony formation). No spheres arose from nonpigmented single cells. In addition, when the nonpigmented (low side scatter) fraction was plated after FACS, no pigmented spheres formed $(n=4)$. Thus, single pigmented cells can be FACS isolated and rare pigmented cells give rise to clonal sphere colonies consisting of pigmented and nonpigmented cells.

\section{Sphere colonies are self-renewing and multipotential}

Sphere colonies were characterized for expression of genes involved in retinal development. Using quantitative RT-PCR we found that Rx and Pax6 were highly upregulated in hESCderived spheres compared with hESCs, while the pluripotency gene Oct4 had highly reduced expression (Figure 2E), and that spheres also expressed low levels of transcription factors involved in photoreceptor differentiation, $\mathrm{Crx}$ and $\mathrm{Nrl}$ as well as rhodopsin. Sectioned sphere colonies were immunostained for rhodopsin but sufficient protein was not detected in single cells.

To test whether colonies exhibited self-renewal, we passaged colonies using enzymatic dissociation to a single cell suspension both in bulk and as single spheres. A small number 
of clonal secondary spheres formed in both conditions $(18.2 \pm 5.6$ spheres/2,500 bulk cells, $2.6 \pm 0.4$ spheres/single sphere, Figure $2 \mathrm{~F}$ ). This number was increased 2 -fold by the addition of ROCK inhibitor $\left(5.4 \pm 0.7\right.$ spheres/single sphere, $\left.t_{98}=3.60, \mathrm{p}<0.5\right)$. Single pigmented cells were observed to give rise to secondary spheres and all secondary spheres contained some pigmented cells. We also found that cells could be expanded as monolayers in $10 \%$ FBS, with a single-cell derived sphere giving rise to $3.2 \pm 1.7$ million cells after 3 passages $(n=6)$. This is an underestimation, as trypsinization to a single cell suspension was associated with cell loss.

When differentiated on laminin-coated plates in the presence of 1\% FBS, hESC-derived colonies produced bestrophin-positive RPE cells as well as neurons and glia after 4 weeks (Figure 3). Rhodopsin-positive cells were only rarely observed ( $<1 \%$ of cells), though the low levels of $\mathrm{Crx}, \mathrm{Nrl}$ and rhodopsin mRNA in sphere colonies suggested that hESC-derived colonies have the potential to differentiate into rod photoreceptors. This was tested this by co-culturing cells with retinal explants. Primary spheres were labeled with GFP-expressing lentivirus by infecting single pigmented cells 24 hours after FACS. Spheres were then dissociated into small clumps and co-cultured with adult or embryonic neural retinal explants. Approximately 50\% of surviving cells were found in the outer nuclear layer. All of cells in the outer nuclear layer either expressed rhodopsin or remained pigmented and undifferentiated. (Figure 4A), while cells residing in other retinal layers were all rhodopsinnegative. No cells developed outer segments, though some extended short processes. This indicates that the progeny of RSCs derived from hESC colonies can upregulate photoreceptor markers given the appropriate environment.

\section{hESC-derived colonies can integrate into the RPE and neural retina after transplantation into the neonatal mouse eye}

To determine whether hESC-derived RSCs could produce multilineage retinal progeny in vivo, we transplanted dissociated clonal sphere colonies that had been labeled with GFPexpressing lentivirus into the developing, early postnatal mouse retina. 1-5\% of transplanted cell survived after 3-4 weeks, which is similar to findings after transplantation of human eye-derived RSCs and mouse retinal progenitors (Coles et al., 2004; Inoue et al., 2010; MacLaren et al., 2006). $>90 \%$ of the surviving cells were integrated into the RPE or were found between the RPE and photoreceptor nuclei (Figure 4B-E). All cells in the RPE were pigmented and expressed bestrophin (Figure 4B, C), while cells adjacent to the outer nuclear layer expressed rhodopsin (Figure 4D). More rarely ( $<10 \%$ of cells), nuclei were observed integrated into the outer nuclear layer or into other retinal layers (Figure 4E). These results are similar to what is seen after transplantation of mouse CE-derived RSC colonies, multilineage differentiation with preferential integration into the RPE and presence in the subretinal space (Ballios and van der Kooy, 2010).

\section{hESC-derived RSCs can be directed to a photoreceptor fate in vitro by addition of exogenous factors}

Retinoic acid (RA) and taurine have been shown to drive mouse and human RSC progeny to a photoreceptor fate (Ballios et al., 2012). These factors were added to our differentiation media to determine if a similar effect was found in RSCs derived from hESCs. The differentiation period employed for mRSCs was 44 days, and we expected a more protracted course with human cells. Serum was maintained in the hESC-derived colony differentiation media, as survival beyond 4-6 weeks was extremely low in serum-free differentiation media. Colonies were allowed a 5-10 day expansion period in FBS with FGF before RA and taurine were added to the media. Under these conditions, most cells remained undifferentiated at 8 weeks, staining positive for the progenitor marker Pax6 (Figure 4F). By Q-PCR, the rod-specific marker Nrl marker was upregulated at 4 weeks, a $20.9 \pm 12.2$-fold 
increase over hESC levels, and remained high at 8 weeks, $14.3 \pm 4.8$-fold higher than hESCs and 77-fold higher than at day 0 of RA and taurine ( $\mathrm{n}=5$ each). No rhodopsin mRNA was detected at day 0 of differentiation conditions $(n=2)$, but low levels started to be expressed at 8 weeks, $0.56 \pm 0.7$-fold of the levels in sphere colonies (not detected in hESCs, $\mathrm{n}=5$ ). Rhodopsin-positive cells by immunocytochemistry were very rare $(<1 \%$ of cells) at 8 weeks of differentiation, however, by 16 weeks, $20.6 \pm 3.2 \%$ of cells were rhodopsin-positive (Figure 4G-I). In addition, 16 week differentiated cells cultured for an additional 7 days on early postnatal retinal explants were $47 \%$ rhodopsin positive and a subset of these cells displayed outer segment-like morphology (Figure 4J). Thus, hESCderived RSCs can be directed toward a rod photoreceptor fate.

\section{Discussion}

ESCs acquire a neural identity in the absence of exogenous factors (Tropepe et al., 2001; Smukler et al., 2006) and neural progenitors specifically will adopt a rostral identity (Gaspard et al., 2008; Wataya et al., 2008). The eye is derived from the embryonic forebrain at the telencephalon/diencephalon border and ESCs allowed to differentiate in minimal media on MEFs for long periods will subsequently give rise to retinal progenitors (Figure 1, (Klimanskaya et al., 2004; Meyer et al., 2009)). Retinal cells also arise from primate ESCs exposed to stromal cell-derived inducing activity, which previously was demonstrated to be neuralizing (Kawasaki et al., 2002). These data suggest that retinal specification may be a default fate for a subset of cells following neural induction (Eiraku et al., 2011).

The first studies focusing on these differentiation protocols characterized the pigmented cells that arose as specific RPE progenitors, which could be expanded to give rise to large sheets of RPE (Kawasaki et al., 2002; Klimanskaya et al., 2004). These conditions also give rise to neural retinal cells (Figure 1, (Meyer et al., 2009)), however the clonal derivation of pigmented and nonpigmented cells from a single RSC-like cell has not been demonstrated previously. Other studies using small molecules to derive neural retinal precursors reported the concomitant emergence of pigmented cells (Ikeda et al., 2005; Osakada et al., 2008), suggesting that bipotential (RPE and neural retinal), optic vesicle-like progenitors are generated, and that embryonic retinal development is recapitulated in vitro (Meyer et al., 2009).

RSCs are pigmented cells found in the CE of the adult mammalian eye that also have the capacity to give rise to both RPE and retinal neurons and glia. We find that RSCs are contained within the pigmented cells that arise spontaneously in differentiating hESCs. These cells may be the origin of both neural retina and RPE colonies, or may represent a stem cell compartment that only emerges later within the RPE compartment. Pigment itself is not an early RSC marker, as pigmentation only appears in vivo after morphogenesis of the optic cup (Buse and de Groot, 1991). It also does not appear to have a functional role, as RSCs can easily be isolated from albino animals (Tropepe et al., 2000). Muller glia also have been suggested to act as RSCs, however, clonal analyses have not been performed to assay for multipotentiality and self-renewal. Moreover, Muller cells have not been demonstrated to give rise to pigmented epithelial cells and make only a very limited contribution to retina regeneration even after a combination of retinal injury and growth factors or genetic manipulation (Ooto et al., 2004; Wan et al., 2007; Osakada et al., 2007).

Pigmented Chx10 and Pax6-double positive cells have not been described in the developing eye. Pax6 is expressed throughout the optic cup and in early RPE and neural retinal progenitors, but $\mathrm{Chx} 10$ is a specific marker of the inner optic cup that will give rise to the neural retina (Liu et al., 1994). Single Chx10-positive cells in our cultures represent restricted neural retinal progenitors with limited or no self-renewal (Tropepe et al., 2000). 
Most pigmented cells were positive only for Pax6 or negative for both markers, indicating that the majority of pigmented cells in our cultures are RPE progenitors or mature RPE. Rare, double positive cells likely represent RSCs and we predict they also would be present in the developing eye at a low frequency. Many double positive cells appeared at the edges of pigmented patches. This may reflect a capacity to give rise to both pigmented and nonpigmented retinal cells, or may simply be a consequence of immunostaining of more centrally located pigmented cells being masked by surrounding, heavily pigmented cells. FACS showed that approximately 1 in 500 pigmented cells proliferated to form colonies, similar to the frequency of RSCs from the human CE (Coles et al., 2004).

Embryonic rodent and chick RPE can be induced to produce neural retina through a transdifferentiation process (Guillemot and Cepko, 1992; Zhao et al., 1995). In this case, the vast majority (>80\%) of pigmented cells become neural retinal cells and they are not thought to go through an undifferentiated stem/progenitor state. We find that a rare subset of pigmented cells derived from hESCs possesses the two cardinal stem cell properties of multipotentiality and self-renewal. RSC colonies derived clonally from hESCs showed selfrenewal in bulk passages, as monolayers and at the level of single clonal colonies. Colonies differentiated into both RPE and multiple neural retinal cell types in vitro and integrated into the developing eye after transplantation. Spheres also could be derived from wells containing single pigmented cells, which then proliferated to produce both pigmented cells and nonpigmented neural retinal progenitor cells. In addition, RSC spheres expressed both the neural retinal-specific progenitor marker Chx10 as well as Pax6 by Q-PCR. These data are inconsistent with a model of aggregated RPE cells simply transdifferentiating to produce neural retinal cells.

hESC-derived RSCs gave rise to a small number of rhodopsin-positive photoreceptors when differentiated for 4 weeks in 1\% FBS. Outer segments were not observed, as mature photoreceptor morphology is never seen with in vitro derived photoreceptors, and is even lost when young photoreceptors are cultured (Ballios et al., Open Biology, 2012). RA and taurine promote rod photoreceptor differentiation in cultured mouse RSCs and also promoted rod differentiation in our hESC-derived RSCs, though cells required a longer differentiation period than the 3-6 weeks used for mouse RSCs (Tropepe et al., 2000; Ballios et al., 2012). Human eye development takes place over a much longer time course than in mouse. $\mathrm{Nrl}$ precedes rhodopsin expression by approximately 7 days in mouse (Akimoto et al., 2006) but in humans, this difference is around 5 weeks (Hendrickson et al., 2008). We observed a similar delay between $\mathrm{Nrl}$ and rhodopsin expression in our cultures, suggesting that a normal developmental timeline is followed in hESC-derived RSC rod differentiation. Other studies have reported similar prolonged time courses to observe photoreceptor differentiation from hESCs. Very low numbers of rhodopsin positive cells have been detected after 2-3 weeks of differentiation (Lamba et al., 2006). Meyer et al., first reported opsin at day 70 (Meyer et al., 2009) and one group reported no opsin expression after 130 days of differentiation and less than $10 \%$ rhodopsin-positive cells even at day 200 (Osakada et al., 2008).

The formation of elongated outer segments was not observed after transplantation of RSCs derived from hESCs into the developing eye. This lack of full morphological photoreceptor differentiation also has been reported after transplantation of mouse Muller glial or embryonic retinal progenitors (Wan et al., 2008; Singhal et al., 2008; Yang et al., 2002; Qiu et al., 2005; Tomita et al., 2006). A single demonstration of outer segment formation after transplantation of retinal progenitors exists in a study using cells derived from $\mathrm{hESCs}$ (Lamba et al., 2009), however, cell fusion was not ruled out as a potential origin of labeled photoreceptors. When this group used the same protocol to differentiate human iPSCs but then specifically selected for committed photoreceptors, no outer segments formed after 
transplantation (Lamba et al., 2010). While this could represent an important difference between hESCs and iPSCs, it has been previously shown using mouse neural retinal cell transplants that there is a critical window in the timing of photoreceptor development that results in successful integration and morphological differentiation after transplantation (MacLaren et al., 2006). It is possible that similar transplantation of partially differentiated cells would result in mature rod photoreceptor differentiation, however, we have not yet determined the appropriate timing for hESC derived RSC progeny differentiation.

A recent study reported the in vitro derivation of complete optic cups followed by production of mature neural retinal cells types arranged in appropriate layers from mouse ESCs (Eiraku et al., 2011). While exciting, this finding will need to be replicated in human cells. In addition, the use of ESC-derived cells for therapeutic purposes requires the elimination of residual pluripotent cells due to their potential tumorgenicity. We describe a protocol for clonal isolation of pigmented cells that selects for specified RSCs. Degenerative diseases of the eye often affect only one retinal cell type, in many cases, photoreceptors. RSC colonies can produce multiple retinal cell types. Moreover, they can be specifically directed toward a rod photoreceptor fate and, in principle, other desired retinal cells.

hRSCs are potentially a useful cell population in cellular therapy to replace photoreceptors and other cells lost in retinal degenerative disease, however, obtaining autologous tissue is technically difficult and cadaveric donors are limited. hESC-derived RSCs are a potentially unlimited source of retinal cells that can be directed to a photoreceptor fate, and if derived instead from iPSCs (Meyer et al., 2009; Hirami et al., 2009), would avoid immunological rejection. Clonal selection of pigmented cells would eliminate carry over of undifferentiated and potentially tumorigenic cells. We have also shown that bona fide hRSCs emerge in an in vitro model of retinal development. These cultures represent a useful and readily available system for investigating the mechanism of hRSC specification and their differentiation into specific retinal cells.

\section{Acknowledgments}

We thank members of the van der Kooy groups for helpful discussion. We thank Rod McInnes for sharing antibodies. The anti Pax6 antibody developed by A. Kawakami was obtained from the Developmental Studies Hybridoma Bank developed under the auspices of the NICHD and maintained by The University of Iowa, Department of Biology, Iowa City, IA 52242. LC and BGB are supported by a Canadian Institutes of Health Research (CIHR) MD/PhD studentship. BGB also holds a McLaughlin Centre Graduate Fellowship, a University of Toronto Open Fellowship and a McLaughlin Centre for Molecular Medicine award. This work was supported by the CIHR and NIH (R01 EY015716) (DvdK).

\section{Abbreviations}

$\begin{array}{ll}\text { hESC } & \text { human embryonic stem cell } \\ \text { RSC } & \text { retinal stem cell } \\ \text { CE } & \text { ciliary epithelium } \\ \text { RPE } & \text { retinal pigmented epithelium } \\ \text { RA } & \text { retinoic acid }\end{array}$

\section{References}

Ahmad I, Tang L, Pham H. Identification of neural progenitors in the adult mammalian eye. Biochem Biophys Res Commun. 2000; 270:517-521. [PubMed: 10753656]

Akimoto M, Cheng H, Zhu D, Brzezinski JA, Khanna R, Filippova E, Oh EC, Jing Y, Linares JL, Brooks M, Zareparsi S, Mears AJ, Hero A, Glaser T, Swaroop A. Targeting of GFP to newborn 
rods by $\mathrm{Nrl}$ promoter and temporal expression profiling of flow-sorted photoreceptors. Proc Natl Acad Sci U S A. 2006; 103:3890-3895. [PubMed: 16505381]

Ballios BG, Clarke L, Coles B, Shoichet M, van der Kooy D. The adult retinal stem cell is a rare cell in the ciliary epithelium whose progeny can differentiate into photoreceptors. Biology Open. 201210.1242/bio.2012027

Ballios BG, Cooke MJ, van der Kooy D, Shoichet MS. A hydrogel-based stem cell delivery system to treat retinal degenerative diseases. Biomaterials. 2010; 31:2555-2564. [PubMed: 20056272]

Bäumer N, Marquardt T, Stoykova A, Spieler D, Treichel D, Ashery-Padan R, Gruss P. Retinal pigmented epithelium determination requires the redundant activities of Pax2 and Pax6. Development. 2003; 130:2903-2915. [PubMed: 12756174]

Buse E, de Groot H. Generation of developmental patterns in the neuroepithelium of the developing mammalian eye: the pigment epithelium of the eye. Neurosci Lett. 1991; 126:63-66. [PubMed: 1866085]

Chaddah R, Arntfield M, van der Kooy D. Clonal derivation of neural stem cells from human embryonic stem cells. J Neurosci. Submitted.

Coles BL, Angénieux B, Inoue T, Del Rio-Tsonis K, Spence JR, McInnes RR, Arsenijevic Y, van der Kooy D. Facile isolation and the characterization of human retinal stem cells. Proc Natl Acad Sci U S A. 2004; 101:15772-15777. [PubMed: 15505221]

Eiraku M, Takata N, Ishibashi H, Kawada M, Sakakura E, Okuda S, Sekiguchi K, Adachi T, Sasai Y, Eiraku M, Takata N, Ishibashi H, Kawada M, Sakakura E, Okuda S, Sekiguchi K, Adachi T, Sasai Y. Self-organizing optic-cup morphogenesis in three-dimensional culture. Nature. 2011; 472:51-56. [PubMed: 21475194]

Furukawa T, Kozak CA, Cepko CL. rax, a novel paired-type homeobox gene, shows expression in the anterior neural fold and developing retina. Proc Natl Acad Sci U S A. 1997; 94:3088-3093. [PubMed: 9096350]

Gaspard N, Bouschet T, Hourez R, Dimidschstein J, Naeije G, van den Ameele J, Espuny-Camacho I, Herpoel A, Passante L, Schiffmann SN, Gaillard A, Vanderhaeghen P. An intrinsic mechanism of corticogenesis from embryonic stem cells. Nature. 2008; 455:351-357. [PubMed: 18716623]

Graw J. Eye development. Curr Top Dev Biol. 2010; 90:343-386. [PubMed: 20691855]

Grindley JC, Davidson DR, Hill RE. The role of Pax-6 in eye and nasal development. Development. 1995; 121:1433-1442. [PubMed: 7789273]

Guillemot F, Cepko CL. Retinal fate and ganglion cell differentiation are potentiated by acidic FGF in an in vitro assay of early retinal development. Development. 1992; 114:743-754. [PubMed: 1377624]

Heller J, Jones P. Purification of bovine retinal pigment epithelial cells by dissociation in calcium free buffers and centrifugation in Ficoll density gradients followed by "recovery" in tissue culture. Exp Eye Res. 1980; 30:481-487. [PubMed: 7409007]

Hendrickson A, Bumsted-O'Brien K, Natoli R, Ramamurthy V, Possin D, Provis J. Rod photoreceptor differentiation in fetal and infant human retina. Exp Eye Res. 2008; 87:415-426. [PubMed: 18778702]

Hirami Y, Osakada F, Takahashi K, Okita K, Yamanaka S, Ikeda H, Yoshimura N, Takahashi M. Generation of retinal cells from mouse and human induced pluripotent stem cells. Neurosci Lett. 2009; 458:126-131. [PubMed: 19379795]

Ikeda H, Osakada F, Watanabe K, Mizuseki K, Haraguchi T, Miyoshi H, Kamiya D, Honda Y, Sasai N, Yoshimura N, Takahashi M, Sasai Y. Generation of Rx+/Pax6+ neural retinal precursors from embryonic stem cells. Proc Natl Acad Sci U S A. 2005; 102:11331-11336. [PubMed: 16076961]

Inoue T, Coles BL, Dorval K, Bremner R, Bessho Y, Kageyama R, Hino S, Matsuoka M, Craft CM, McInnes RR, Tremblay F, Prusky GT, van der Kooy D. Maximizing functional photoreceptor differentiation from adult human retinal stem cells. Stem Cells. 2010; 28:489-500. [PubMed: 20014120]

Kaufman, MH. The atlas of mouse development. London; San Diego: Academic Press; 1992.

Kawasaki H, Suemori H, Mizuseki K, Watanabe K, Urano F, Ichinose H, Haruta M, Takahashi M, Yoshikawa K, Nishikawa S, Nakatsuji N, Sasai Y. Generation of dopaminergic neurons and 
pigmented epithelia from primate ES cells by stromal cell-derived inducing activity. Proc Natl Acad Sci U S A. 2002; 99:1580-1585. [PubMed: 11818560]

Klimanskaya I, Hipp J, Rezai KA, West M, Atala A, Lanza R. Derivation and comparative assessment of retinal pigment epithelium from human embryonic stem cells using transcriptomics. Cloning Stem Cells. 2004; 6:217-245. [PubMed: 15671670]

Lamba DA, Gust J, Reh TA. Transplantation of human embryonic stem cell-derived photoreceptors restores some visual function in Crx-deficient mice. Cell Stem Cell. 2009; 4:73-79. [PubMed: 19128794]

Lamba DA, Karl MO, Ware CB, Reh TA. Efficient generation of retinal progenitor cells from human embryonic stem cells. Proc Natl Acad Sci U S A. 2006; 103:12769-12774. [PubMed: 16908856]

Lamba DA, McUsic A, Hirata RK, Wang PR, Russell D, Reh TA. Generation, purification and transplantation of photoreceptors derived from human induced pluripotent stem cells. PLoS One. 2010; 5:e8763. [PubMed: 20098701]

Liu IS, Chen JD, Ploder L, Vidgen D, van der Kooy D, Kalnins VI, McInnes RR. Developmental expression of a novel murine homeobox gene (Chx10): evidence for roles in determination of the neuroretina and inner nuclear layer. Neuron. 1994; 13:377-393. [PubMed: 7914735]

Lund RD, Wang S, Klimanskaya I, Holmes T, Ramos-Kelsey R, Lu B, Girman S, Bischoff N, Sauvé Y, Lanza R. Human embryonic stem cell-derived cells rescue visual function in dystrophic RCS rats. Cloning Stem Cells. 2006; 8:189-199. [PubMed: 17009895]

MacLaren RE, Pearson RA, MacNeil A, Douglas RH, Salt TE, Akimoto M, Swaroop A, Sowden JC, Ali RR. Retinal repair by transplantation of photoreceptor precursors. Nature. 2006; 444:203-207. [PubMed: 17093405]

Meyer JS, Shearer RL, Capowski EE, Wright LS, Wallace KA, McMillan EL, Zhang SC, Gamm DM. Modeling early retinal development with human embryonic and induced pluripotent stem cells. Proc Natl Acad Sci U S A. 2009; 106:16698-16703. [PubMed: 19706890]

Oliver G, Mailhos A, Wehr R, Copeland NG, Jenkins NA, Gruss P. Six3, a murine homologue of the sine oculis gene, demarcates the most anterior border of the developing neural plate and is expressed during eye development. Development. 1995; 121:4045-4055. [PubMed: 8575305]

Ooto S, Akagi T, Kageyama R, Akita J, Mandai M, Honda Y, Takahashi M. Potential for neural regeneration after neurotoxic injury in the adult mammalian retina. Proc Natl Acad Sci U S A. 2004; 101:13654-13659. [PubMed: 15353594]

Osakada F, Ikeda H, Mandai M, Wataya T, Watanabe K, Yoshimura N, Akaike A, Akaike A, Sasai Y, Takahashi M. Toward the generation of rod and cone photoreceptors from mouse, monkey and human embryonic stem cells. Nat Biotechnol. 2008; 26:215-224. [PubMed: 18246062]

Osakada F, Ooto S, Akagi T, Mandai M, Akaike A, Takahashi M. Wnt signaling promotes regeneration in the retina of adult mammals. J Neurosci. 2007; 27:4210-4219. [PubMed: 17428999]

Qiu G, Seiler MJ, Mui C, Arai S, Aramant RB, de Juan E, Sadda S. Photoreceptor differentiation and integration of retinal progenitor cells transplanted into transgenic rats. Exp Eye Res. 2005; 80:515-525. [PubMed: 15781279]

Quinn JC, West JD, Hill RE. Multiple functions for Pax6 in mouse eye and nasal development. Genes Dev. 1996; 10:435-446. [PubMed: 8600027]

Singhal S, Lawrence JM, Bhatia B, Ellis JS, Kwan AS, Macneil A, Luthert PJ, Fawcett JW, Perez MT, Khaw PT, Limb GA. Chondroitin sulfate proteoglycans and microglia prevent migration and integration of grafted Müller stem cells into degenerating retina. Stem Cells. 2008; 26:1074-1082. [PubMed: 18218817]

Smukler SR, Runciman SB, Xu S, van der Kooy D. Embryonic stem cells assume a primitive neural stem cell fate in the absence of extrinsic influences. J Cell Biol. 2006; 172:79-90. [PubMed: 16390999]

Tomita M, Mori T, Maruyama K, Zahir T, Ward M, Umezawa A, Young MJ. A comparison of neural differentiation and retinal transplantation with bone marrow-derived cells and retinal progenitor cells. Stem Cells. 2006; 24:2270-2278. [PubMed: 17008430]

Tropepe V, Coles BLK, Chiasson BJ, Horsford DJ, Elia AJ, McInnes RR, van der Kooy D. Retinal stem cells in the adult mammalian eye. Science. 2000; 287:2032-2036. [PubMed: 10720333] 
Tropepe V, Hitoshi S, Sirard C, Mak TW, Rossant J, van der Kooy D. Direct neural fate specification from embryonic stem cells: a primitive mammalian neural stem cell stage acquired through a default mechanism. Neuron. 2001; 30:65-78. [PubMed: 11343645]

Wan J, Zheng H, Chen ZL, Xiao HL, Shen ZJ, Zhou GM. Preferential regeneration of photoreceptor from Müller glia after retinal degeneration in adult rat. Vision Res. 2008; 48:223-234. [PubMed: 18155124]

Wan J, Zheng H, Xiao HL, She ZJ, Zhou GM. Sonic hedgehog promotes stem-cell potential of Müller glia in the mammalian retina. Biochem Biophys Res Commun. 2007; 363:347-354. [PubMed: 17880919]

Watanabe K, Ueno M, Kamiya D, Nishiyama A, Matsumura M, Wataya T, Takahashi JB, Nishikawa S, Nishikawa S, Muguruma K, Sasai Y. A ROCK inhibitor permits survival of dissociated human embryonic stem cells. Nat Biotechnol. 2007; 25:681-686. [PubMed: 17529971]

Wataya T, Ando S, Muguruma K, Ikeda H, Watanabe K, Eiraku M, Kawada M, Takahashi J, Hashimoto N, Sasai Y. Minimization of exogenous signals in ES cell culture induces rostral hypothalamic differentiation. Proc Natl Acad Sci U S A. 2008; 105:11796-11801. [PubMed: 18697938]

Xu S, Sunderland ME, Coles BL, Kam A, Holowacz T, Ashery-Padan R, Marquardt T, McInnes RR, van der Kooy D. The proliferation and expansion of retinal stem cells require functional Pax6. Dev Biol. 2007; 304:713-721. [PubMed: 17316600]

Yang P, Seiler MJ, Aramant RB, Whittemore SR. Differential lineage restriction of rat retinal progenitor cells in vitro and in vivo. J Neurosci Res. 2002; 69:466-476. [PubMed: 12210840]

Zhao S, Thornquist SC, Barnstable CJ. In vitro transdifferentiation of embryonic rat retinal pigment epithelium to neural retina. Brain Res. 1995; 677:300-310. [PubMed: 7552256]

Zuber ME, Gestri G, Viczian AS, Barsacchi G, Harris WA. Specification of the vertebrate eye by a network of eye field transcription factors. Development. 2003; 130:5155-5167. [PubMed: 12944429] 

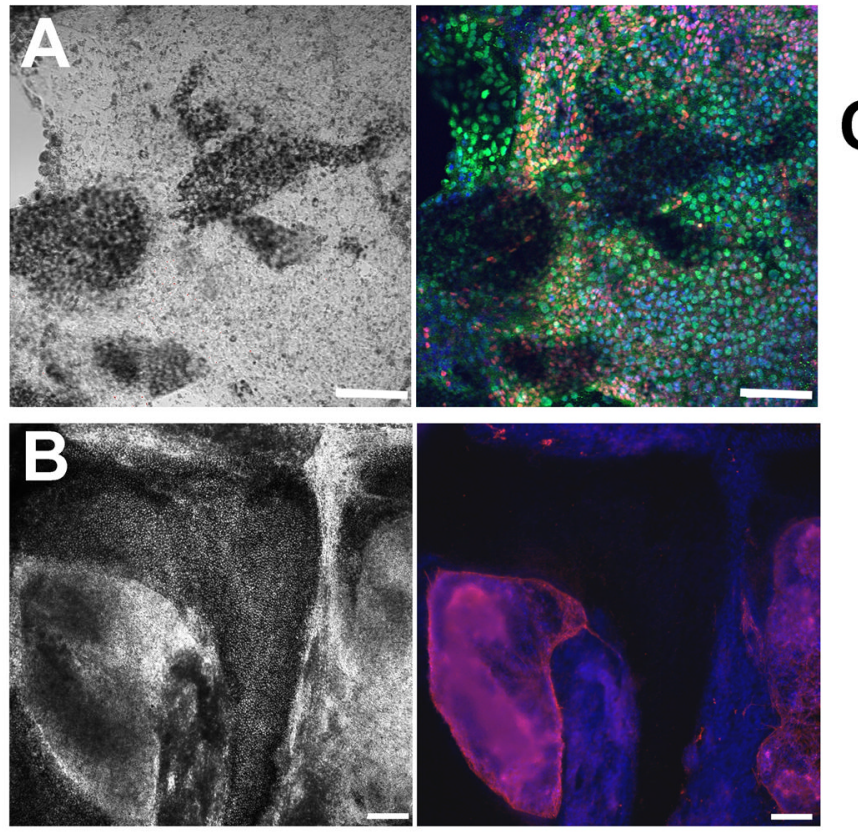
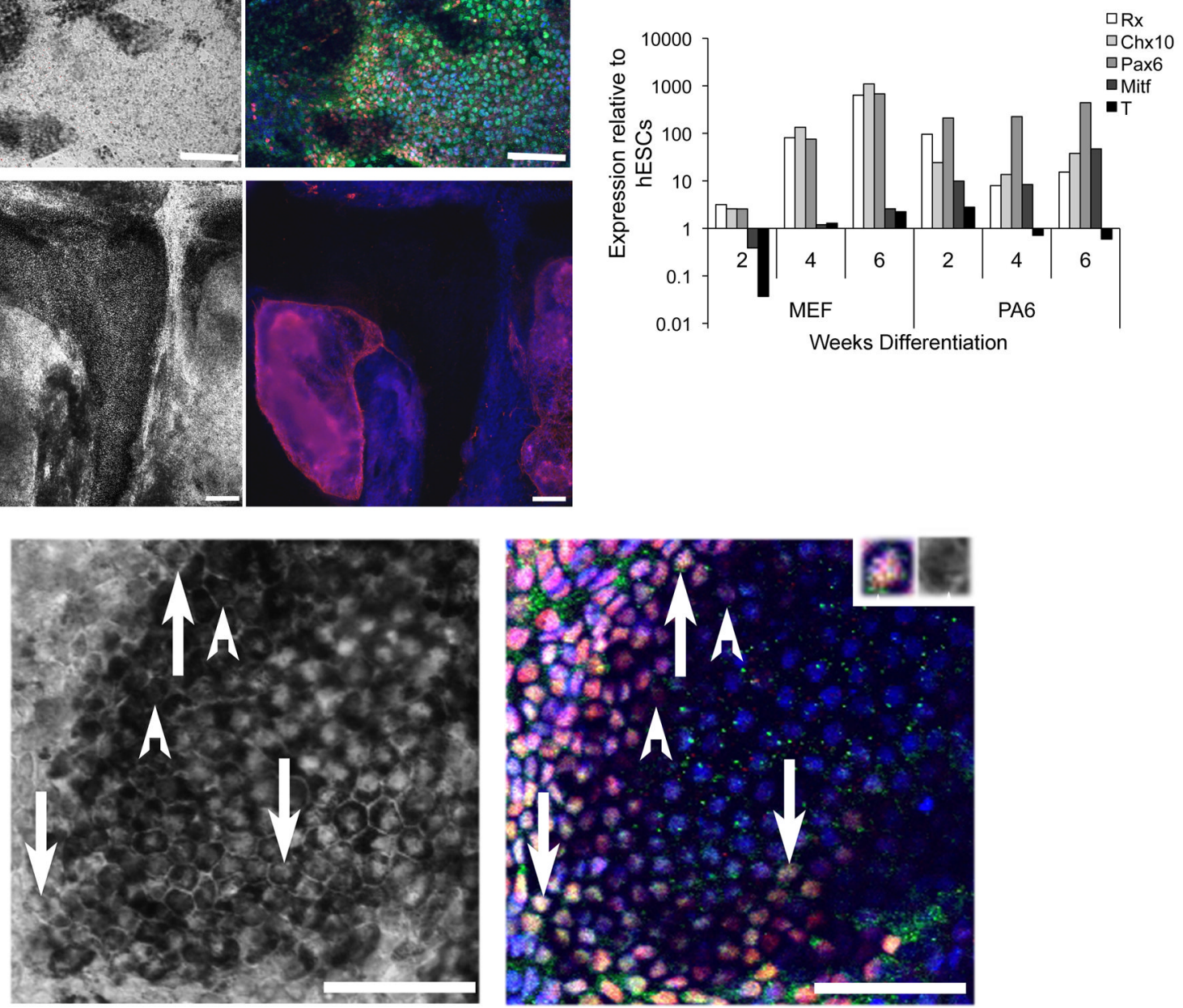

Figure 1.

hESCs differentiate into retinal cells in the absence of exogenous factors. (A) Pigmented patches (grey scale, left) in 12 week differentiated hESCs on MEFs were found along with Pax6-positive (red, right panel) neural/retinal and Chx10-positive (green) neural retinal progenitors/neurons. Scale bar, 100 $\mu \mathrm{m}$. (B) Clusters of neuron-specific progenitors were

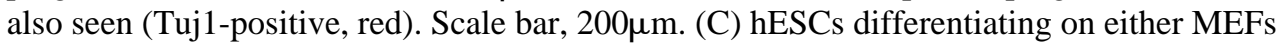
or PA6 stromal cells upregulated early retinal transcription factors by Q-PCR, but not the mesodermal marker brachyury $(\mathrm{T})$ or the pluripotency marker Oct4. Levels were normalized to starting hESCs. (D) Confocal images show that rare pigmented cells co-expressed nuclear Pax6 (red) and Chx10 (green), indicating that some pigmented cells are undifferentiated retinal progenitor cells (white arrows, right panel inset shows an enlargement of a single Pax6- Chx10-positive pigmented cell). Pigmented cells often expressed Pax6 alone (white arrowheads). Scale bar, 50 $\mu \mathrm{m}$. Nuclei are counterstained with Hoechst (blue). 
A

$\mathbf{E}$

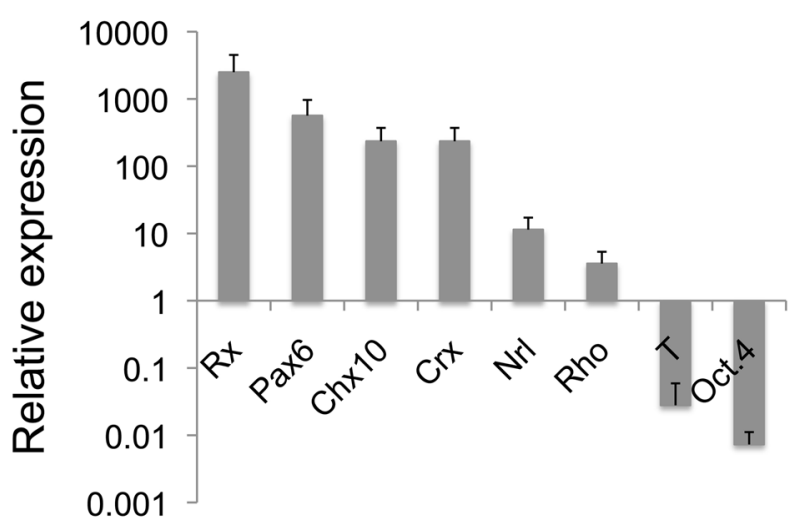

Figure 2.
B
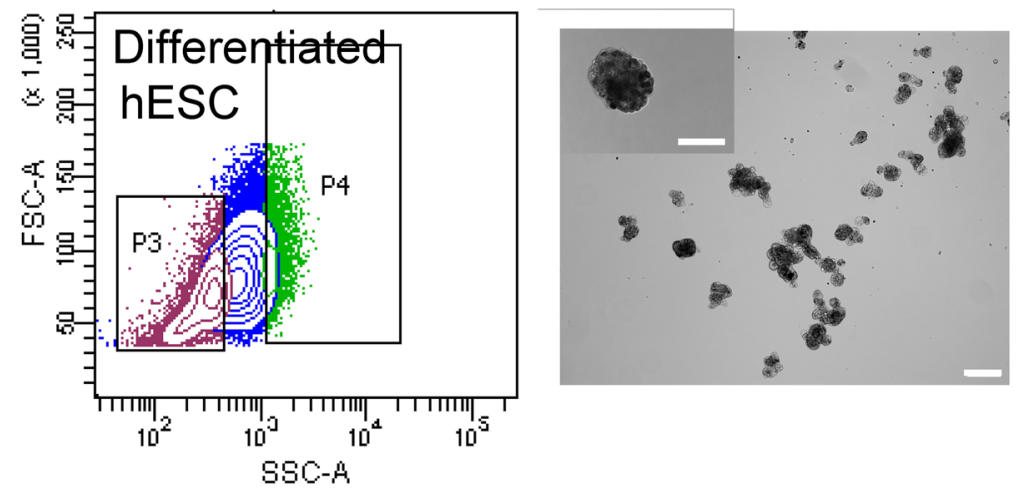

D

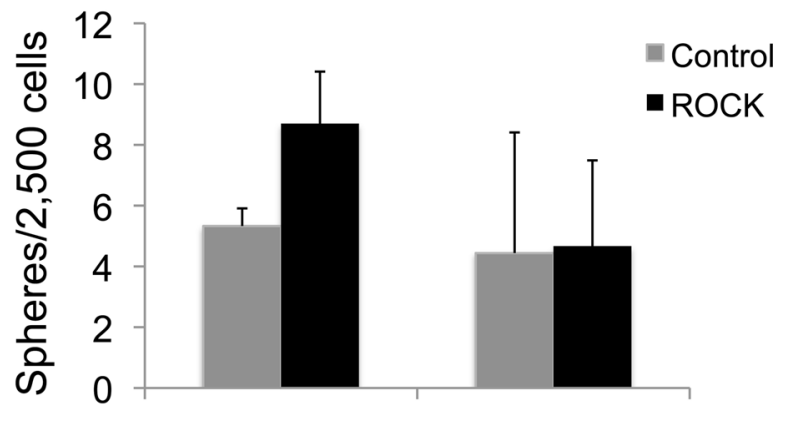

Ficoll

Single pigmented cells give rise to self-renewing colonies. Pigmented cells could be isolated using FACS. A high side scatter (SSC) population was not present in cells from undifferentiated hESCs (A, left) but was seen in differentiated hESC colonies (A, right) and contained pigmented cells. Rare single pigmented cells plated in serum-free media with FGF gave rise to colonies containing pigmented and nonpigmented cells. (B) shows sphere colonies collected together in the center of a field after counting. Scale bar, $200 \mu \mathrm{m}$, inset, $100 \mu \mathrm{m}$. (C) Pigmented cells could also be isolated by centrifugation using a ficoll gradient. There was no significant difference in sphere frequency between FACS and ficoll $\left(F_{1,11}=0.59, p>0.5\right)$ or after the addition of ROCK inhibitor $\left(F_{1,11}=0.54, p>0.5\right)$. (D) 
Example of a colony derived from a well with a single cell pigmented cell. Scale bar, $50 \mu \mathrm{m}$. (E) Q-PCR revealed expression of early retinal transcription factors in sphere colonies, as well as low levels of more differentiated markers, $\mathrm{Crx}, \mathrm{Nrl}$ and rhodopsin (Rho) but not the mesoderm marker brachyury $(\mathrm{T})$ or the pluripotency marker Oct4. Levels are normalized to hESCs. (F) Colonies could be passaged in bulk (spheres/2,500 cells) and as single spheres. Passaged spheres also formed from single pigmented cells (inset, representative images of single cells on day 3,10 and 21 after passaging). Single sphere passaging was significantly improved in the presence of ROCK inhibitor $\left(\mathrm{t}_{98}=3.60, \mathrm{p}<0.5\right)$. Scale bars, $50 \mu \mathrm{m}$. All data is shown + SEM. 

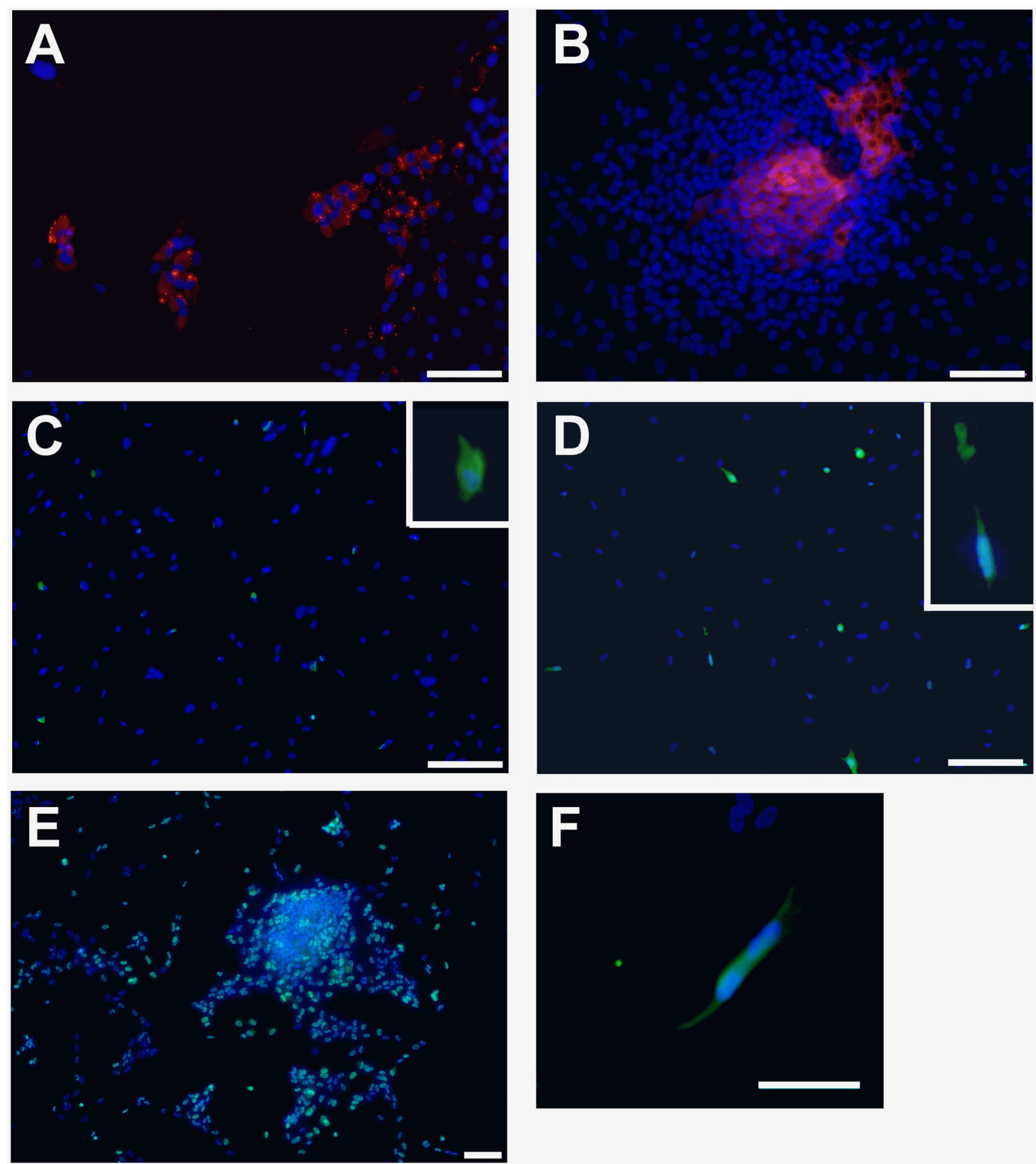

Figure 3.

hESC-derived colonies differentiate into RPE cells, neurons and glia in 1\% FBS. RPE cells expressing bestrophin (A), Cralbp-positive Muller glia (B), and Tuj1-(C) and calbindinpositive neurons (D) were detected after 4 weeks. Many undifferentiated cells were present,

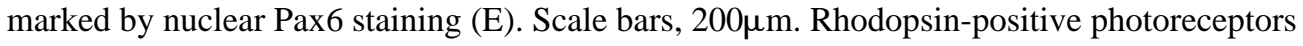
were rare $(\mathrm{F}$, a few or none in each differentiated clonal colony). Scale $50 \mu \mathrm{m}$. Nuclei are counterstained with Hoechst (blue). 

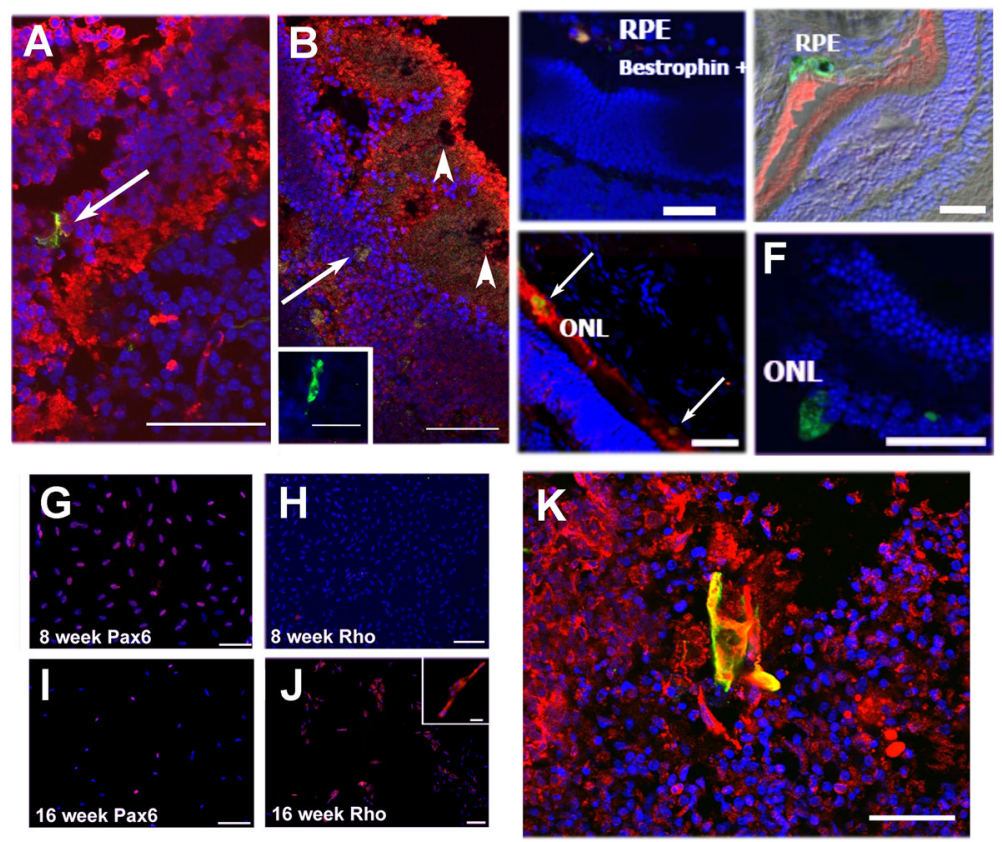

Figure 4.

Cells from hESC-derived colonies can differentiate into rhodopsin-positive cells. $50 \%$ of surviving GFP-labeled cells settled in the outer nuclear layer and expressed rhodopsin when co-cultured with adult neural retina (A, B-arrows, rhodopsin-red). They often extended short processes but did not show fully mature photoreceptor morphology (A). The remaining 50\% of the cells either retained pigment and stayed undifferentiated (B, arrowheads) or were found in other retinal layers and were rhodopsin negative (B, inset: inner nuclear layer). Scale bars, $50 \mu \mathrm{m}$, B inset $25 \mu \mathrm{m}$. Dissociated GFP-marked primary sphere cells also integrated into the developing eye after transplantation into the vitreous fluid of neonatal NOD/SCID mice. Many of the surviving cells integrated into the RPE and expressed the marker bestrophin (B, red-human specific antibody) and were pigmented (C). Cells expressing rhodopsin (D) were also found between the RPE and outer nuclear layer (ONL) (red-rhodopsin in C, D marking rod photoreceptors). Some nuclei were seen integrated into neural retinal layers (E). Scale bars B-E, $40 \mu \mathrm{m}$. Rod photoreceptor differentiation could be induced in culture using RA and taurine. At 8 weeks of differentiation in RA and taurine most cells remained undifferentiated Pax6-positive progenitors (F, red) and rhodopsinpositive cells were rare $(G$, red). By 16 weeks, few cells were Pax6-positive $(H)$ and the number positive for rhodopsin had greatly increased (I). Scale bars F-I, 200 $\mu \mathrm{m}$, I inset, $50 \mu \mathrm{m}$. (J) 16 week differentiated rhodopsin-positive cells cultured on perinatal retinal explants for an additional 7 days extended outer segment-like processes. Scale bar, $40 \mu \mathrm{m}$. Nuclei are counterstained with Hoechst (blue). 